BARRETT'S OESOPHAGUS

\title{
A randomised controlled trial of ablation of Barrett's oesophagus with multipolar electrocoagulation versus argon plasma coagulation in combination with acid suppression: long term results
}

\author{
P Sharma, S Wani, A P Weston, A Bansal, M Hall, S Mathur, A Prasad, R E Sampliner
}

See end of article for authors' affiliations

Correspondence to: Correspondence to: Gastroenterology (11 11$)$, Department of Veterans Affairs Medical Center, 4801 E Linwood Blvd, Kansas City, MO 641282295, USA; psharma@ kumc.edu

Received

16 November 2005

Accepted for publication

21 January 2006

Published online first

21 April 2006
Gut 2006;55:1233-1239. doi: 10.1136/gut.2005.086777

Background: Many modalities have been used to ablate Barrett's oesophagus (BO). However, long term results and comparative effectiveness are unknown.

Aims: Our aim was to compare the long term efficacy of achieving complete reversal (endoscopic and histological) between multipolar electrocoagulation (MPEC) and argon plasma coagulation (APC) in BO patients and assess factors influencing successful ablation.

Methods: Patients with BO, 2-6 cm long, underwent 24 hour $\mathrm{pH}$ testing on proton pump inhibitor (PPI) therapy. Patients were then randomised by BO length to undergo ablation with MPEC or APC every 48 weeks until endoscopic reversal or maximal of six treatment sessions.

Results: Thirty five BO patients have been followed for at least two years following endoscopic ablation, 16 treated with MPEC and 19 with APC. There was complete reversal of BO in 24 patients $(69 \%) ; 75 \%$ with MPEC and $63 \%$ with APC $(p=0.49)$. There was no difference in the number of sessions required in the two groups. There was no difference in age, $\mathrm{pH}$ results, $\mathrm{BO}$ length, PPI dose, or hiatal hernia size between patients with and without complete reversal. One patient developed an oesophageal stricture but there were no major complications such as bleeding or perforation.

Conclusions: In BO patients treated with MPEC or APC in combination with acid suppression, at long term follow up, complete reversal of $\mathrm{BO}$ can be maintained in approximately $70 \%$ of patients, irrespective of the technique. There are no predictors associated with achieving complete reversal of BO. Continued surveillance is still indicated in the post ablative setting. As yet, these techniques are not ready for clinical application (other than for high grade dysplasia or early oesophageal adenocarcinoma) and cannot be offered outside the research arena.
B arrett's oesophagus (BO) is an acquired condition resulting from severe oesophageal mucosal injury due to gastro-oesophageal reflux disease (GORD). BO is characterised by replacement of normal squamous oesophageal epithelium by metaplastic intestinal epithelium containing goblet cells. ${ }^{12}$ Approximately $10 \%$ of patients with chronic GORD are diagnosed with BO. BO is the premalignant lesion for the majority of patients with oesophageal and gastro-oesophageal junction adenocarcinoma. ${ }^{3}$ Oesophageal adenocarcinoma (OAC) is a highly lethal cancer and continues to be the most rapidly rising cancer in the USA and the Western world. ${ }^{5}$ The relative risk of developing OAC in $\mathrm{BO}$ patients appears to be 30 times that of the general population. ${ }^{6}$ The goal of therapy in patients with $\mathrm{BO}$ is to control reflux symptoms and promote healing of erosive oesophagitis. Reducing oesophageal exposure to gastric acid has been the cornerstone of modern GORD and BO therapy, with the hope that this treatment will reverse Barrett's metaplasia and/or halt malignant progression to adenocarcinoma. ${ }^{7}$

Theoretically, eliminating the Barrett's epithelium could decrease or eliminate the cancer risk. Unfortunately, neither medical (profound acid inhibition) nor surgical (fundoplication) therapies for reflux appear to achieve complete regression of $\mathrm{BO}$ and elimination of its cancer risk. Antireflux surgery failed to convincingly demonstrate, in prospective and retrospective studies, a reduction in the extent of Barrett's epithelium and in the risk of malignant transformation..$^{8-10}$ In the same way, longstanding intensive acid reducing measures by pharmacological means did not show, in a consistent manner, a reduction in the extent of $\mathrm{BO}$ or a halt in the evolution to neoplastic transformation. ${ }^{11-13}$

A number of ablative techniques in combination with reduction of oesophageal acid exposure, pharmacologically or surgically, have been developed in attempts to reverse BO. These include thermal ablation with lasers (neodymiumyttrium aluminum garnet (Nd-YAG), potassium titanium phosphate (KTP)), argon plasma coagulation (APC), multipolar electrocoagulation (MPEC), non-thermal ablation with photodynamic therapy (PDT), and cryotherapy. Ablative techniques are based on the hypothesis that injury of the metaplastic epithelium in an acid reduced environment would reverse the pathophysiological sequence that led to the development of $\mathrm{BO}$ and subsequently lead to the restoration of the normal squamous lining. ${ }^{14}$ Preliminary results using these techniques have been promising but few long term results are available. The long term stability of the resulting neosquamous epithelium remains unclear. It is also unclear which form of therapy is most efficacious in achieving complete ablation of $\mathrm{BO}$ or which is best tolerated by patients.

Abbreviations: $B O$, Barrett's oesophagus; MPEC, multipolar electrocoagulation; APC, argon plasma coagulation; PPI, proton pump inhibitor; GORD, gastro-oesophageal reflux disease; OÁC, oesophageal adenocarcinoma; Nd-YAG, neodymium-yttrium aluminium garnet; KTP, potassium titanium phosphate; PDT, photodynamic therapy; HH, hiatal hernia; HGD, high grade dysplasia; LGD, low grade dysplasia 
The goals of this study were: (1) to compare the efficacy of achieving complete reversal (endoscopic and histological) of BO between MPEC and APC; (2) to evaluate the stability of the neosquamous epithelium after two years of follow up; and (3) to determine clinical factors (age, BO length, hiatal hernia size, proton pump inhibitor (PPI) dose, and 24 hour intraoesophageal $\mathrm{pH}$ control) that may help predict complete reversal of $\mathrm{BO}$.

\section{METHODS \\ Patients}

This study was conducted at two sites: the Veterans Affairs Medical Center, Kansas City, Missouri and the Southern Arizona Veterans Affairs Health Care System, Tucson, Arizona from February 2000 to December 2004. A total of 35 patients with BO that presented for surveillance endoscopy with a length of 2-6 cm were prospectively recruited for a trial of ablation by either MPEC or APC. Patients were randomised by $\mathrm{BO}$ length (stratified randomisation using sealed opaque envelopes) to undergo ablation with MPEC or APC every 4-8 weeks until there was endoscopic reversal or a maximal of six treatment sessions. All patients underwent 24 hour $\mathrm{pH}$ monitoring while on rabeprazole $20 \mathrm{mg}$ twice a day. Patient demographics (age, sex, race), BO length, hiatal hernia $(\mathrm{HH})$ size were recorded. Exclusion criteria were as follows: a history of any oesophageal surgery, $\mathrm{BO}$ with high grade dysplasia (HGD) or cancer, oesophageal stricture, oesophageal or gastric varices, age $<18$ years, allergy to PPI, uncontrolled coagulopathy, and patients with uncontrolled significant comorbidities. The study was approved by the Human Subjects Committee at both institutions and all patients gave written informed consent prior to enrolment.

\section{Endoscopy}

Upper endoscopy was performed using therapeutic video endoscopes (Olympus 2T-100 and 1T-140; Olympus America Inc, Melville, New York, USA). BO was defined by the presence of a columnar lined distal oesophagus, with intestinal metaplasia, characterised by acid mucin containing goblet cells using combined haematoxylin and eosin-alcian blue pH 2.5 stain. ${ }^{15}$ Four quadrant biopsies were obtained every $2 \mathrm{~cm}$ using jumbo biopsy forceps (Microvasive Corp., Natick, Massachusetts, USA). Biopsies were performed using the turn and suction technique to maximise biopsy size. If there was endoscopic evidence of erosive or ulcerative oesophagitis, the grade of oesophagitis was recorded and patients were asked to return for endoscopy after 2-3 months of treatment with a higher dosage of PPI. The length of the BO segment was defined as the distance from the incisors to the end of the oesophagus minus the distance from the incisors to the proximal margin of continuous appearing Barrett's epithelium. ${ }^{12}$ The gastro-oesophageal junction was identified by the proximal margin of the gastric folds coinciding with the pinch at the end of the tubular oesophagus. ${ }^{16} \mathrm{HH}$ size was measured from the gastrooesophageal junction to the diaphragmatic pinch. Helicobacter pylori infection was determined by obtaining at least eight biopsies from the stomach (antrum, body, and cardia).

\section{Oesophageal pH testing}

Twenty four hour ambulatory intraoesophageal $\mathrm{pH}$ monitoring was performed using a $\mathrm{pH}$ catheter connected to a portable digital data recorder that stored $\mathrm{pH}$ data for up to 24 hours (Mark III Medtronics, Minneapolis, Minnesota, USA). The $\mathrm{pH}$ electrode was passed transnasally and the distal end of the probe was placed $5 \mathrm{~cm}$ above the lower oesophageal sphincter. $\mathrm{pH}$ testing was done at least seven days after PPI therapy was started. Data were analysed using a PC with a standard software program (pw base model, pw EsopHogram reflux analysis model) and Polygram for Windows 2.0 (Medtronics Inc). The percentage of time with $\mathrm{pH}<4.0$ in the distal oesophagus was analysed separately for total, upright, and supine periods. Persistent abnormal acid reflux was defined as a distal oesophageal $\mathrm{pH}<4$ for longer than $4.2 \%$ of the total monitoring period. During upright and supine positions, an oesophageal $\mathrm{pH}<4$ for more than $6.3 \%$ and $1.5 \%$ of the respective monitoring periods was considered abnormal.

\section{Endoscopic ablation treatment}

After interpretation of the initial endoscopic and biopsy results, patients were randomised, using sealed opaque envelopes. Randomisation was stratified by BO length $(<3 \mathrm{~cm} v \geqslant 3 \mathrm{~cm})$ to undergo ablation with MPEC or APC.

Thermal ablation with MPEC of Barrett's mucosa was performed using a 10F Gold Probe (Microvasive, Natick, Massachusetts, USA). A $60 \mathrm{~W}$ energy source (ERBE USA Inc., Marietta, Georgia, USA) at a setting of $20 \mathrm{~W}$ and continuous power were used for all treatment sessions. Patients randomised to APC were treated with continuous pulses by using a $10 \mathrm{~F}(3.2 \mathrm{~mm})$ forward firing APC probe and generator (Argon Plasma Coagulator; ERBE USA Inc.), at a power setting of $60 \mathrm{~W}$ and a gas flow of $1.4-1.8 \mathrm{l} / \mathrm{min}$. Treatment of the entire Barrett's segment was attempted at each session. Ablation of $\mathrm{BO}$ was initiated at the gastrooesophageal junction and thermal energy was applied with mild tangential force (MPEC) or without contact (APC) using a linear paint stroke technique until a white coagulum was visualised in the targeted segment of Barrett's epithelium (fig 1). Distal treatment did overlap with the pinch at the end of the tubular oesophagus coinciding with the proximal margin of the gastric folds. Patients were interviewed by telephone 48-72 hours after each treatment session to assess the presence and severity of treatment related symptoms, including fever, nausea, vomiting, sore throat, dysphagia, odynophagia, haematemesis, melena, shortness of breath, and chest pain. Endoscopic treatment sessions were continued at 4-8 week intervals until there was no endoscopic evidence of BO. At the final endoscopy, visual elimination of

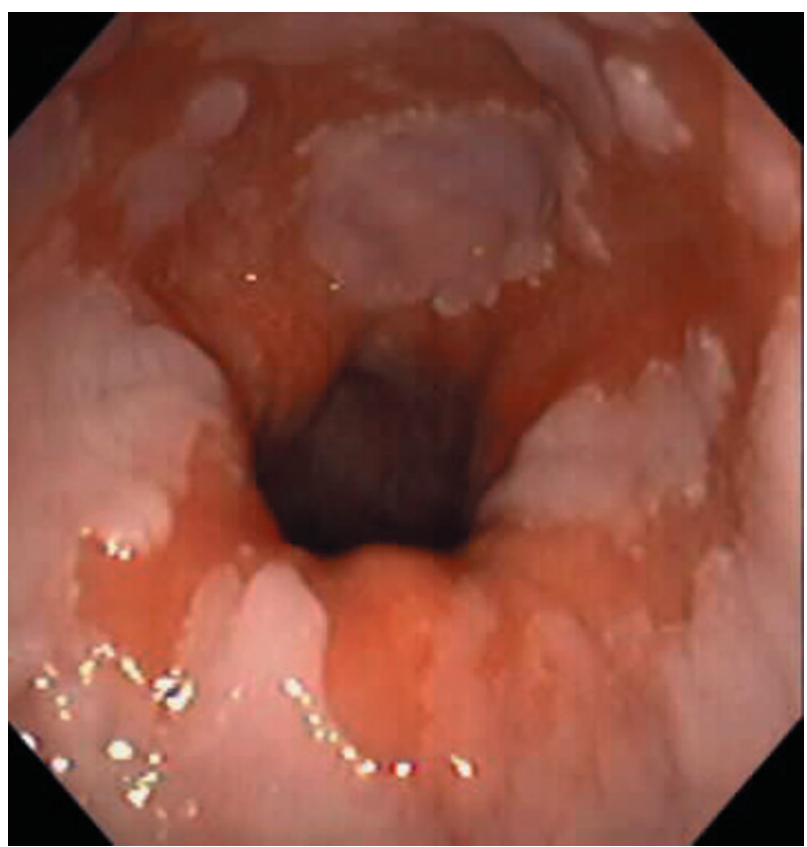

Figure 1 Endoscopic view of a patient with Barrett's oesophagus before first ablation therapy with argon plasma coagulation. 


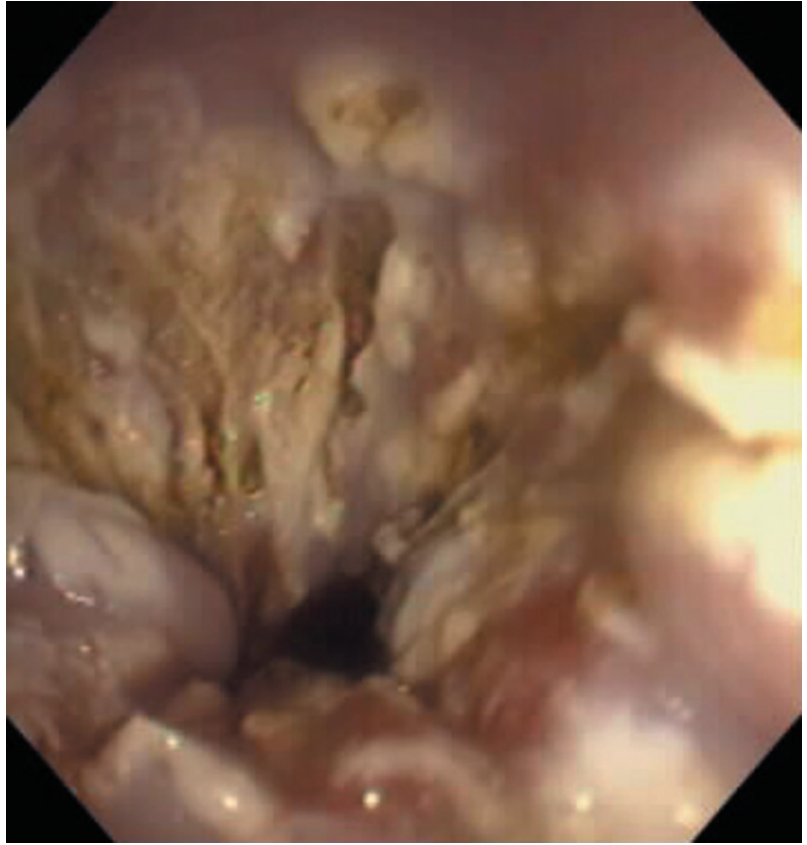

Figure 2 Endoscopic view of the typical coagulation necrosis seen after ablation therapy with argon plasma coagulation.

Barrett's was noted (fig 2) and confirmed by spraying 10$20 \mathrm{ml}$ of $2.5 \%$ solution of Lugol's iodine over the former extent of Barrett's mucosa to highlight potential residual areas (negative staining with Lugol's) to target for further therapy. Treatment was conducted on an outpatient basis. Once intestinal metaplasia was documented as eliminated, PPI dose was decreased to $20 \mathrm{mg}$ daily or to the dose that eliminated reflux symptoms. All patients underwent surveillance endoscopy with biopsies per study protocol at six, 12, and 24 month intervals.

\section{Histology}

All biopsy specimens were fixed in Bouin's solution or $10 \%$ neutral buffered formaldehyde and then embedded in paraffin. Sections were cut from the paraffin blocks and stained with haematoxylin and eosin in combination with alcian blue stain at $\mathrm{pH}$ 2.5. Specimens were examined for the presence of intestinal metaplasia, diagnosed by the presence of blue staining goblet cells. Dysplasia in BO was identified by standardised criteria and classified as negative for dysplasia, indeterminate for dysplasia, low grade dysplasia (LGD), HGD, and invasive adenocarcinoma. For the purpose of statistical analysis, the categories of indeterminate for dysplasia and LGD were considered together. Dysplasia was recognised by the presence of cytological and architectural abnormalities within the glandular epithelium. Each biopsy specimen was examined specifically for the full thickness of squamous epithelium, including the entire basal layer. Special attention was paid to the presence of any goblet cells either within or below the squamous mucosa, which would be indicative of residual intestinal metaplasia. Presence of $H$ pylori infection was documented by histology from the gastric biopsies, including evaluation of Steiner stained sections, if required.

\section{End points}

The primary end point of the study was comparison of the efficacy of the two ablation modalities (MPEC $v$ APC) in achieving endoscopic and histological reversal of BO. Secondary end points included side effects of endoscopic therapy, number of treatment sessions necessary for reversal in the two groups, and clinical factors (age, BO length, $\mathrm{HH}$ size, PPI dose, and pH scores) that may help predict complete reversal of $\mathrm{BO}$.

\section{Statistical analysis}

A statistical software program (SAS, version 8.0; SAS Institute Inc., SAS Campus Drive, Cary, North Carolina, USA) was used for data management and analysis. Categorical variables were summarised by frequencies and percentages and continuous variables were summarised by medians and ranges. Fisher's exact tests (for dichotomous covariates) and Wilcoxon rank sum tests (for continuous covariates) were used to study the effect of BO length, $\mathrm{pH}$ scores, $\mathrm{HH}$ size, and ablation modality in achieving $\mathrm{BO}$ reversal and to compare demographic characteristics of the MPEC and APC populations. Logistic regression was also employed to further examine differences in the two subject groups in a multivariate fashion. For the primary outcome, to determine if MPEC can ablate BO in $90 \%$ of the patients and assuming that APC can ablate Barrett's in $65 \%$, it was determined that 40 patients would be needed in order to detect a significant difference between the two with $80 \%$ power and a type 1 error rate of 5\% using Fisher's test for paired dichotomous responses. These assumptions were based on preliminary data acquired as part of a nonrandomised trial of $\mathrm{BO}$ ablation.

\section{RESULTS}

\section{Clinical and endoscopic characteristics}

Thirty five patients with BO have been followed for at least two years after endoscopic ablation. There were 22 patients that completed the study at the Veterans Affairs Medical Center, Kansas City, Missouri, USA and 13 at the Southern Arizona Veterans Affairs Health Care System, Tucson, Arizona, USA. Sixteen patients were treated with MPEC and 19 with APC. Baseline demographic and clinical characteristics of the study population are summarised in table 1 . The study group was comprised of 34 (97.1\%) males and median age was 62 years (range 32-84). On endoscopy, median BO length was $3 \mathrm{~cm}$ (range 2-6) and median HH size was $3 \mathrm{~cm}$ (range 0-6). No oesophageal strictures or ulcers were identified in any of the studied patients. Three patients (6.5\%) tested positive for $H$ pylori infection using histology. Three of the recruited patients $(6.5 \%)$ had LGD and the remainder had non-dysplastic BO. All patients tolerated rabeprazole well and there were no withdrawals because of side effects. All patients were compliant with the prescribed treatment and this was confirmed by pill count.

Table 1 Baseline demographics, and clinical, endoscopic, and ambulatory 24 hour $\mathrm{pH}$ characteristics of the study patients

\begin{tabular}{ll}
\hline \multicolumn{2}{l}{ Patient characteristics } \\
\hline $\mathrm{n}$ & 35 \\
Age (y) (median (range)) & $62(32-84)$ \\
Sex (Male) & $34(97.1 \%)$ \\
$\mathrm{BO}$ length (cm) (median (range)) & $3(2-6)$ \\
Hiatal hernia size (cm) (mean (SD)) & $3(0-6)$ \\
Helicobacter pylori infection & $3(8.6 \%)$ \\
24 hour pH monitoring & \\
Total time pH <4 (\%) (median (range)) & $0.6(0-29.9)$ \\
Supine time pH $<4$ (\%) (median (range)) & $0(0-47.2)$ \\
Upright time pH $<4(\%)$ (median (range)) & $0.7(0-47.9)$ \\
Maintenance PPI dose (mg) (median (range)) & $20(20-80)$ \\
\hline
\end{tabular}

BO, Barrett's oesophagus; PPI: proton pump inhibitor. 


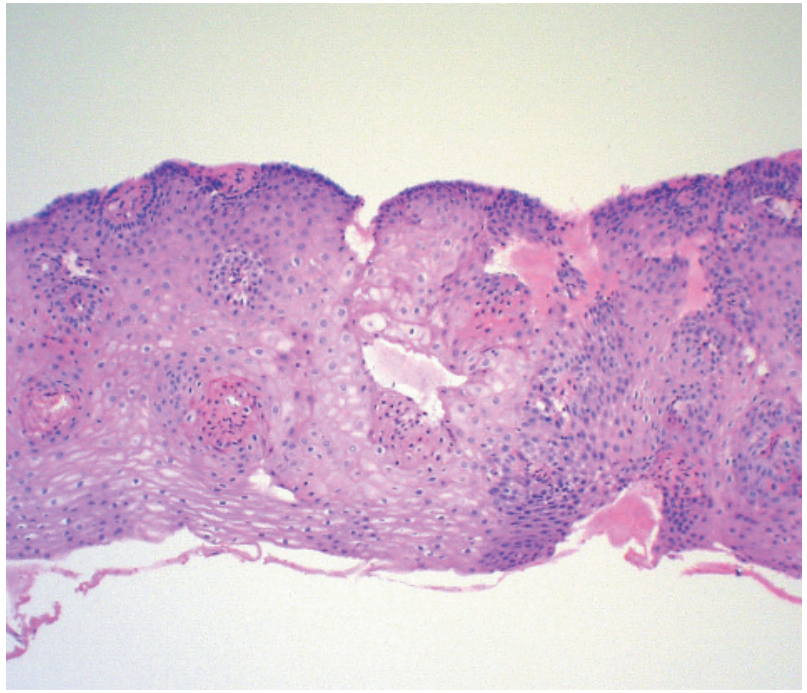

Figure 3 Photomicrograph of post ablation therapy biopsy specimen of former Barrett's segment showing neosquamous epithelium (haematoxylin-eosin, 40x).

\section{Ambulatory intraoesophageal pH monitoring}

Median values for $\mathrm{pH}$ testing were as follows: total per cent time $\mathrm{pH}<4$ was $0.6 \%$ (range $0-29.9 \%$ ), upright per cent time $\mathrm{pH}<4$ was $0.7 \%$ (range $0-47.9 \%$ ), and supine per cent time $\mathrm{pH}<4$ was $0.0 \%$ (range $0-47.2 \%$ ). Twenty six of the $\mathrm{BO}$ patients $(74.3 \%)$ treated with rabeprazole had a normal $\mathrm{pH}$ study (median total per cent time $\mathrm{pH}<40.2 \%$ ). However, nine patients had an abnormal result (median total per cent time $\mathrm{pH}<49.9 \%$ ) and thus failed to achieve normalisation of their 24 hour intraoesophageal $\mathrm{pH}$. Thus $26 \%$ of BO patients who were enrolled in this study exhibited pathological reflux despite high dose PPI therapy. Five of these nine patients also had abnormal acid reflux in the supine position $(\mathrm{pH}<4$ for $>1.5 \%$ of the supine period) whereas seven of these nine patients had abnormal acid reflux in the upright position $(\mathrm{pH}$ $<4$ for $>6.3 \%$ of the upright monitoring period). Also, three patients who had cumulative acid exposure within the normal range for the entire monitoring period had abnormal acid reflux in the supine position. Therefore, the total number of patients with any abnormal $\mathrm{pH}$ value (that is, total, supine, or upright was $12(34.2 \%))$.

\section{Efficacy of ablative therapy}

Complete endoscopic and histological reversal was documented in $29(82.8 \%)$ patients on first surveillance endoscopy post ablation therapy. At a long term follow up of at least two years, complete endoscopic and histological reversal was achieved in $24(68.5 \%)$ patients. Endoscopic reversal was achieved in $28(80 \%)$ patients (that is, normal appearing squamous epithelium on endoscopy). Biopsies of the treated Barrett's segments showed re-epithelialisation with typical stratified squamous mucosa. All specimens of this squamous tissue resembled normal squamous mucosa characterised by thin, flat, polygonal cells (fig 3). BO was successfully ablated in 12 of $16(75 \%)$ patients treated with MPEC and in 12 of 19 (63\%) patients treated with APC. There was no statistically significant difference in the number of patients that achieved complete reversal in either group $(p=0.49)$. The mean number of endoscopic sessions required was 3.8 in the MPEC group and 3.4 in the APC group $(p=0.48)$. There was no statistically significant difference in the groups of $\mathrm{BO}$ patients treated with MPEC and APC with regard to age $(p=0.18)$, length of $\mathrm{BO}(p=0.52)$, HH size $(p=0.44)$, 24 hour $\mathrm{pH}$ results $(\mathrm{p}=0.90)$, PPI dose $(\mathrm{p}=0.27)$, number of endoscopic ablation treatments $(p=0.76)$, or number of patients that had complete (endoscopic and histological) reversal of $\mathrm{BO}(\mathrm{p}=0.49)$ (table 2$)$. There was no instance of dysplasia or cancer in the initial post ablation surveillance biopsy specimens taken from the entire neosquamous zone. No analysis with regard to $H$ pylori infection was performed as the number of patients infected was too low to allow any reasonable assessment of this variable.

\section{Predictors of reversal of $\mathrm{BO}$ with ablative therapy}

The mean number of endoscopic treatments in patients who achieved complete reversal of $\mathrm{BO}$ and in patients who demonstrated residual intestinal metaplasia was 3.6 and 4.3, respectively. There was no significant difference $(p=0.32)$ in the number of treatments in these two groups of patients. There was also no significant difference in BO length $(\mathrm{p}=0.85)$, total per cent time $\mathrm{pH}<4(\mathrm{p}=1.0)$, abnormal total per cent time $\mathrm{pH}<4(\mathrm{p}=1.0)$, HH size $(p=0.22)$, or maintenance PPI dose $(p=0.57)$. Similarly, there was no association between type of ablation therapy $(p=0.49)$ and ability to achieve complete reversal of BO (table 3). There was also no significant difference in the group of patients that achieved complete reversal of $\mathrm{BO}$ treated with MPEC compared with those treated with APC. The factors evaluated included age, number of treatments, $\mathrm{BO}$ length, total per cent time $\mathrm{pH}<4$, abnormal total per cent time $\mathrm{pH}<4, \mathrm{HH}$ size, and maintenance PPI dose (table 4 ). Differences between groups were tested using univariate and multivariate logistic regression analysis.

\section{Complications}

No major complications, such as gastrointestinal bleeding or perforation, were observed in the study group. Eighteen patients (nine in the MPEC group and nine in the APC group) complained of sore throat, seven patients (five in the MPEC group, two in the APC group) complained of difficulty swallowing post procedure, 10 patients (six in the MPEC

Table 2 Patient characteristics by treatment group

\begin{tabular}{|c|c|c|c|}
\hline & MPEC $(n=16)$ & $\operatorname{APC}(n=19)$ & p Value \\
\hline Age (y) & $60(42-68)$ & $65(32-84)$ & 0.18 \\
\hline $\mathrm{BO}$ length $(\mathrm{cm})$ median(range) & $3(2-6)$ & $4(2-6)$ & 0.52 \\
\hline Hiatal hernia size $(\mathrm{cm})$ (median (range)) & $3(0-6)$ & $3(1-5)$ & 0.44 \\
\hline \multicolumn{4}{|l|}{24 hour $\mathrm{pH}$ monitoring } \\
\hline Total time $\mathrm{pH}<4(\%)$ (median (range)) & $0.6(0-29.9)$ & $0.6(0-23.9)$ & 0.90 \\
\hline Supine time $\mathrm{pH}<4(\%)$ (median (range)) & $0(0-39.6)$ & $0.05(0-47.2)$ & 0.51 \\
\hline Upright time $\mathrm{pH}<4$ (\%) (median (range)) & $0.95(0-47.9)$ & $0.65(0-15.8)$ & 0.57 \\
\hline Maintenance PPI dose (mg) (median (range)) & $20(20-60)$ & $40(20-80)$ & 0.27 \\
\hline No of endoscopic treatments (median (range)) & $4(2-6)$ & $3(2-6)$ & 0.76 \\
\hline $\begin{array}{l}\text { No of patients with BO reversal (\%) } \\
\text { (endoscopic and histological ablation) }\end{array}$ & $12(75.0)$ & $12(63.1)$ & 0.49 \\
\hline
\end{tabular}


Table 3 Comparison of data between patients with complete reversal of Barrett's oesophagus and patients with residual intestinal metaplasia (IM) post ablation

\begin{tabular}{|c|c|c|c|}
\hline & $\begin{array}{l}\text { Complete reversal } \\
(\mathrm{n}=24)\end{array}$ & $\begin{array}{l}\text { Residual IM } \\
(n=11)\end{array}$ & $\mathrm{p}$ Value \\
\hline Age (y) (median (range)) & $61.5(32-78)$ & $66(42-84)$ & 0.13 \\
\hline No of treatments (median (range)) & $3(2-6)$ & $5(2-6)$ & 0.32 \\
\hline $\mathrm{BO}$ length $(\mathrm{cm})$ (median (range)) & $3.5(2-6)$ & $3(2-6)$ & 0.85 \\
\hline \multicolumn{4}{|l|}{24 hour $\mathrm{pH}$ monitoring } \\
\hline Total time $\mathrm{pH}<4(\%)$ (median (range)) & $0.5(0-29.9)$ & $0.7(0-28.2)$ & 1.0 \\
\hline Supine time $\mathrm{pH}<4$ (\%) (median (range)) & $0(0-47.2)$ & $0(0-39.6)$ & 0.54 \\
\hline Upright time $\mathrm{pH}<4(\%)$ (median (range)) & $0.6(0-47.9)$ & $1.1(0-22.1)$ & 0.76 \\
\hline No of patients with normal total pH study (\%) & $18(75)$ & $8(72.7)$ & 1.00 \\
\hline Abnormal & $6(25)$ & $3(27.3)$ & \\
\hline No of patients with normal supine pH study (\%) & $20(83.3)$ & $7(63.6)$ & 0.22 \\
\hline Abnormal & $4(16.7)$ & $4(36.4)$ & \\
\hline $\begin{array}{l}\text { No of patients with normal upright pH study (\%) } \\
\text { Abnormal }\end{array}$ & $\begin{array}{l}18(75) \\
6(25.0)\end{array}$ & $\begin{aligned} 10 & (90.9) \\
1 & (9.1)\end{aligned}$ & 0.39 \\
\hline Hiatal hernia size $(\mathrm{cm})$ (median (range)) & $3(0-6)$ & $3(1-5)$ & 0.22 \\
\hline Maintenance PPI dose (median (range)) & $30(20-60)$ & $20(20-80)$ & 0.57 \\
\hline \multicolumn{4}{|l|}{ Ablation therapy } \\
\hline APC & $12(50.0)$ & $7(63.6)$ & 0.49 \\
\hline MPEC & $12(50.0)$ & $4(36.4)$ & \\
\hline
\end{tabular}

group, four in the APC group) had chest pain, two patients complained of epigastric pain post procedure, and one patient in the APC group had low grade fever post ablation. One patient treated by APC developed an oesophageal stricture that was treated successfully with a single dilatation.

\section{DISCUSSION}

In view of the rapid increase in the incidence of OAC, the search for effective strategies of screening and prevention of OAC has assumed importance. ${ }^{17}{ }^{18}$ The current approach of endoscopic screening and surveillance is labour intensive, expensive and, for the most part, unproven. ${ }^{19}$ A technique that can eliminate $\mathrm{BO}$ and its risk of cancer remains desirable. Ablation of BO involves destruction of epithelium using a variety of endoscopic modalities and maintenance of an acid reduced environment. It has been shown that if the metaplastic epithelium is ablated endoscopically and subsequently healed in an acid reduced environment, the neoepithelium may be normal squamous mucosa.

MPEC, ${ }^{14}{ }^{20-22}$ APC ${ }^{23-27}$ heater probe, ${ }^{28}$ Nd-YAG, argon, and KTP laser ${ }^{29}{ }^{30}$ are different forms of thermal energy that have been utilised endoscopically in an effort to reverse BO. However, long term results of ablation, durability, and comparative efficacies are not known. We studied 35 patients with $\mathrm{BO}$ that were randomised by length to undergo ablation with MPEC or APC every 4-8 weeks in combination with acid suppression until endoscopic reversal or a maximal of six treatment sessions was achieved. All patients underwent 24 hour oesophageal $\mathrm{pH}$ monitoring to evaluate intraoesophageal acid suppression on PPI therapy (rabeprazole $20 \mathrm{mg}$ twice daily). This study demonstrates that BO can be completely reversed (endoscopic and histological) and maintained in approximately $70 \%$ of patients at long term follow up of at least two years. In this study, no specific patient characteristics, including age, BO length, $\mathrm{HH}$ size, acid control during high dose PPI therapy, or type of ablative therapy (MPEC or APC) were significantly associated with incomplete reversal of $\mathrm{BO}$. There were no major complications that were observed and one patient developed an oesophageal stricture that was treated successfully with dilatation.

Thermocoagulation of the columnar epithelium can be achieved using an electrocoagulation probe. Mucosal areas are treated until a uniform white coagulum appears and, compared with other ablation modalities, it is relatively widely available and inexpensive. Side effects appear limited

Table 4 Comparison between patients treated with argon plasma coagulation (APC) and multipolar electrocoagulation (MPEC) that achieved complete reversal of Barrett's oesophagus (BO)

\begin{tabular}{|c|c|c|c|}
\hline & $\begin{array}{l}\text { APC } \\
(n=12)\end{array}$ & $\begin{array}{l}\text { MPEC } \\
(n=12)\end{array}$ & p Value \\
\hline Age (y) (median (range)) & $62(32-78)$ & $60(44-67)$ & 0.51 \\
\hline No of treatments (median (range)) & $3(2-6)$ & $4(2-6)$ & 0.48 \\
\hline $\mathrm{BO}$ length $(\mathrm{cm})$ (median (range)) & $3.5(2-6)$ & $3.5(2-6)$ & 0.81 \\
\hline \multicolumn{4}{|l|}{24 hour $\mathrm{pH}$ monitoring } \\
\hline Total time $\mathrm{pH}<4(\%)$, median (range) & $1.3(0-23.9)$ & $0.3(0-29.9)$ & 0.56 \\
\hline Supine time $\mathrm{pH}<4(\%)$, median (range) & $0(0-47.2)$ & $0(0-39.6)$ & 0.3 \\
\hline Upright time $\mathrm{pH}<4(\%)$, median (range) & $0.7(0-15.8)$ & $0.4(0-47.9)$ & 0.78 \\
\hline No of patients with normal total pH study (\%) & $10(55.6)$ & $8(44.4)$ & 0.64 \\
\hline Abnormal & $2(33.3)$ & $4(66.7)$ & \\
\hline No of patients with normal supine $\mathrm{pH}$ study (\%) & $9(45.0)$ & $11(55.0)$ & 0.59 \\
\hline Abnormal & $3(75.0)$ & $1(25.0)$ & \\
\hline No of patients with normal upright pH study (\%) & $10(55.6)$ & $8(44.4)$ & 0.64 \\
\hline Abnormal & $2(33.3)$ & $4(66.7)$ & \\
\hline Hiatal hernia size $(\mathrm{cm})$ (median (range)) & $3(1-5)$ & $2.5(0-6)$ & 0.97 \\
\hline Maintenance PPI dose (median (range)) & $30(20-60)$ & $30(20-60)$ & 0.87 \\
\hline
\end{tabular}

PPI, proton pump inhibitor. 


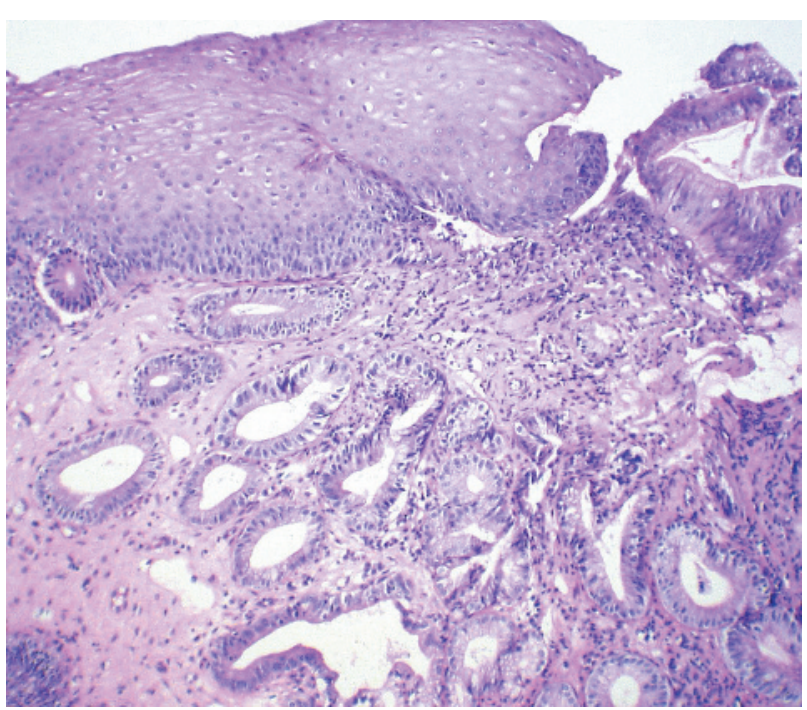

Figure 4 Photomicrograph of post ablation therapy biopsy specimen showing the presence of intestinal metaplasia underlying neosquamous epithelium (haematoxylin-eosin with alcian blue at pH 2.5, 40×).

but include transient dysphagia, odynophagia, chest discomfort, and oesophageal stricture formation. ${ }^{31}$ In a multicentre study, Sampliner and colleagues ${ }^{22}$ studied 58 patients with $\mathrm{BO}$ that were treated with MPEC and high dose PPI therapy. Eighty five per cent had endoscopic reversal and 78\% had both endoscopic and histological reversal. APC is a device used to perform thermal coagulation of tissue. It is a noncontact electrocoagulation device that uses a high frequency monopolar current, which is conducted to tissue via an ionised argon gas. This therapy is purported to have a more superficial depth of tissue injury than PDT or laser. However, unintended contact with the oesophageal mucosa may lead to deeper tissue damage. Reported complications rates have ranged between $0 \%$ and $24 \%$. These include pneumatosis, pneumoperitoneum, subcutaneous emphysema, pain, ulceration, stricture formation, bleeding, perforation, and death. ${ }^{31}$ Van Laethem et al used APC in 31 patients with BO maintained on omeprazole $40 \mathrm{mg}$ daily. ${ }^{23}$ Visual elimination of $\mathrm{BO}$ was achieved in $81 \%$ of patients. However, complete reversal of intestinal metaplasia was achieved in only 19 patients $(61 \%)$. Only a few studies have long term follow up on their patients treated with ablation therapy. Kahaleh et al evaluated the long term outcomes (median follow up 36 months) in patients who underwent APC for BO. Thirty nine patients with BO (seven with LGD) underwent APC and received PPI therapy. By 12 months, over $50 \%$ of patients, regardless of PPI dose, had endoscopic or histological relapse. Two cases of cancer developed in the cohort. ${ }^{32}$ In a long term follow up study of 11 patients (including four with LGD), BO was eliminated after mucosal ablation with MPEC and acid control. Complete reversal (endoscopic and histological) was achieved in $73 \%$ of patients. Durability of the new squamous mucosa was documented over a mean follow up of three years. $^{20}$

There is also a paucity of data on comparison of different treatment modalities. In a recent study, Dulai et al studied 52 BO patients that were randomised to treatment with APC or MPEC combined with high dose PPI therapy. There was no statistically significant difference between the two groups with regard to the mean number of treatments and efficacy to achieve endoscopic and histological reversal of BO. ${ }^{33}$ Hage et al compared 5-aminolevulinic acid (ALA) PDT with APC in 40 patients, with a combination of metaplastic $(n=32)$ and LGD $(n=8)$ on histology. Two different treatment regimens were used for PDT and APC was administered at $65 \mathrm{~W}$. The study reported that fractionated PDT was marginally less effective than APC and that fractionated PDT was as effective as APC, although APC was cheaper and associated with less discomfort during treatment. ${ }^{34}$

Acid suppression is essential for ablation although the degree of control required is controversial. It has been assumed that normalisation of oesophageal acid exposure is essential for complete Barrett's mucosa reversal. ${ }^{35}$ Prior studies have shown that BO can be completely reversed with endoscopic ablation therapy despite abnormal oesophageal acid exposure and patients can fail reversal even with normal oesophageal acid exposure. ${ }^{14212336}$ Shorter length of BO and a normalised $\mathrm{pH}$ on PPI are predictors of successful ablation. $^{23} 2732$

A few limitations of this study merit consideration. As endoscopists cannot be blinded to the treatment group, there is a potential for observer bias in determining one of the end points of interest: endoscopic ablation. The study was conducted in an older male veterans population and hence effect of age and sex may be difficult to assess. Although the sample size was predetermined, recruitment of 40 patients was not possible. However, given the rates of $\mathrm{BO}$ ablation observed in this study (MPEC $75 \%$ and APC 63\%) recruitment of an additional five patients would not change the results. On basis of these results a significant difference could only be detected if 496 subjects were enrolled ( $80 \%$ power, $5 \%$ significance, Fisher's exact test). A large multicentre trail will be needed to study the difference between these two ablative techniques. Patients with a BO length of $>6 \mathrm{~cm}$ were not included in the study and oesophageal motility studies and multichannel intraluminal impedance monitoring was not performed. Finally, the effect of PPI therapy on duodenogastric reflux (bile reflux) with or without acid and intragastric acid suppression on PPI therapy in these patients was not measured.

One of the important questions that remains unanswered is whether ablation can decrease the risk of OAC. Persistence of underlying intestinal metaplasia (fig 4) after ablation is not specific for MPEC or APC and a number of investigators using various modes of ablative techniques, including PDT and argon laser have reported this finding. ${ }^{20-23} 3738$ Residual intestinal metaplasia carries with it the potential to progress to dysplasia and/or adenocarcinoma. ${ }^{39}{ }^{40}$ Therefore, surveillance endoscopy with procurement of biopsies from the area of former Barrett's is currently recommended, even after reversal therapy. The ability of ablation therapy to decrease the cancer risk of patients with $\mathrm{BO}$ can be proved only if these patients are followed long term, but given that $30 \%$ of patients have persistent intestinal metaplasia, this appears unlikely.

What is the current clinical implication of these ablative techniques? Currently, ablative therapy may be considered in patients with HGD or intramucosal carcinoma that are not operative candidates or those that prefer a non-surgical approach to their disease. In patients with HGD/early OAC undergoing ablation with PDT or undergoing endoscopic mucosal resection, APC or MPEC can be used to ablate the surrounding non-dysplastic tissue. Endoscopic ablation therapy is not for all patients with $\mathrm{BO}$ as a minority will progress to HGD and/or cancer. Identifying this subgroup of patients should be the first step for selecting candidates for reversal therapy. Further research may identify biological markers to better define the subset of patients appropriate for such a therapeutic approach. The natural history of BO, risk factors for progression, level of acid suppression required for treatment and maintenance of neosquamous epithelium, efficacy of different ablation techniques, and documentation of decreased cancer risk are a few important issues that 
should be addressed in future studies. Until then, these techniques are not ready for clinical application (other than for HGD or early OAC) and cannot be offered outside the research arena.

\section{Authors' affiliations}

P Sharma, S Wani, A P Weston, A Bansal, M Hall, S Mathur, A Prasad, R E Sampliner, University of Kansas School of Medicine and Veterans Affairs Medical Center, Kansas City, Missouri, and Southern Arizona Veterans Affairs Health Care System and Arizona Health Sciences Center, Tucson, Arizona, USA

*Supported by the Veterans Affairs Medical Center, Kansas City, MO, and a grant from Eisai/Janssen.

Conflict of interest: None declared.

\section{REFERENCES}

1 Sampliner RE. Practice parameters committee of the ACG. Updated guidelines for the diagnosis, surveillance and therapy of Barrett's esophagus. Am J Gastroenterol 2002:97:1888-95.

2 Fitzgerald RC, Triadafilopoulus G. Recent developments in the molecular characterization of Barrett's esophagus. Dig Dis Sci 1998;16:63-80.

3 Phillips RW, Wong RKH. Barrett's esophagus: natural history, incidence, etiology and complications. Gastroenterol Clin North Am 1991;20:791-816.

4 Reid BJ. Barrett's esophagus and esophageal adenocarcinoma. Gastroenterol Clin N Am 1991;20:817-34.

5 Blot WJ, McLaughlin JK. The changing epidemiology of esophageal cancer. Semin Oncol 1999;26:2-8

6 Anderson LA, Murray U, Murphy SJ, et al. Mortality in Barrett's oesophagus: results from population based study. Gut 2003:52:1081-4.

7 Carlson N, Lechago J, Richter J, et al. Acid suppression therapy may not alter malignant progression in Barrett's metaplasia showing p53 protein accumulation. Am J Gastroenterol 2002;97:1340-5.

8 Sagar $\mathbf{P}$, Ackroyd R, Hosie K, et al. Regression and progression of Barrett's esophagus after anti-reflux surgery. Br J Surg 1995;82:806-10.

9 Williamson W, Ellis F, Gibb S, et al. Effective antireflux operation on Barrett's mucosa. Ann Thorac Surg 1990;49:537-42.

10 McDonald ML, Trastek VF, Allen MS, et al. Barrett's esophagus: does an antireflux procedure reduce the need for endoscopic surveillance? J Thorac Cardiovasc Surg 1996; 111:1135-40.

11 Sharma P, Sampliner R, Camargo E. Normalization of esophageal pH with high dose proton pump inhibitor therapy does not result in regression of Barrett's esophagus. Am J Gastroenterol 1997:92:582-5.

12 Sampliner RE, Garewal HS, Fennerty MB, et al. Lack of impact of therapy on extent of Barrett's esophagus in 67 patients. Dig Dis Sci 1990;35:93-6.

13 Peters F, Ganesh S, Ruipers E, et al. Endoscopic regression of Barrett's oesophagus during omeprazole treatment: a randomized double blind study. Gut 1999:45:489-94.

14 Sampliner RE, Fennerty MB, Garewal HS. Reversal of Barrett's esophagus with acid suppression and multipolar electrocoagulation: preliminary results. Gastrointest Endosc 1996;44:523-5.

15 Yeh RW, Gerson LB, Triadafilopoulos G. Efficacy of esomeprazole in controlling reflux symptoms, intraesophageal, and intragastric $\mathrm{pH}$ in patients with Barrett's esophagus. Dis Esophagus 2003;16:193-8.

16 McClave S, Boyce H, Gottfried M. Early diagnosis of columnar-lined esophagus: a new endoscopic diagnostic criterion. Gastrointest Endosc 1987:33:413-16.

17 Haggitt R. Adenocarcinoma of the esophagus: A new epidemic? Hum Pathol 1992;23:475-6.

18 Blot W, Devesa S, Fraumeni J. Continuing climb in rates of esophageal adenocarcinoma: An update. JAMA 1993;270:1320.
19 Sharma P, McQuaid K, Dent J, et al. A critical review of the diagnosis and management of Barrett's esophagus: The AGA Chicago Workshop. Gastroenterology 2004; 127:310-30

20 Sharma P, Bhattacharya A, Garewal HS, et al. Durability of new squamous epithelium after endoscopic reversal of Barrett's esophagus. Gastrointest Endosc 1999;50:159-64

21 Kovacs BJ, Chen YK, Lewis TD, et al. Successful reversal of Barrett's esophagus with multipolar electrocoagulation despite inadequate acid suppression. Gastrointest Endosc 1999:49:547-53.

22 Sampliner RE, Faigel D, Fennerty MB, et al. Effective and safe endoscopic reversal of nondysplastic Barrett's esophagus with thermal electrocoagulation combined with high-dose acid inhibition: a multicenter study. Gastrointest Endosc 2001;53:554-8.

23 Van Laethem JL, Cremer M, Peny MO, et al. Eradication of Barrett's mucosa with argon plasma coagulation and acid suppression: immediate and mid term results. Gut 1998;43:747-51.

24 Mork H, Barth T, Kreipe HH, et al. Reconstitution of squamous epithelium in Barrett's esophagus with endoscopic argon plasma coagulation: a prospective study. Scand J Gastroenterol 1998;33:1130-4.

25 Pereira-Lima JC, Busnello JV, Saul C, et al. High power setting argon plasma coagulation for the eradication of Barrett's esophagus. Am J Gastroenterol 2000;95:1661-8.

26 Basu KK, Pick B, Bale R, et al. Efficacy and one year follow up of argon plasma coagulation therapy for ablation of Barrett's oesophagus: factors determining persistence and recurrence of Barrett's epithelium. Gut 2002;51:776-80.

27 Ackroyd R, Tam W, Schoeman M, et al. Prospective randomized controlled trial of argon plasma coagulation ablation vs. endoscopic surveillance of patients with Barrett's esophagus after antireflux surgery. Gastrointest Endosc 2004:59:1-7.

28 Montes CG, Brandalise NA, Deliza R, et al. Antireflux surgery followed by bipolar electrocoagulation in the treatment of Barrett's esophagus. Gastrointest Endosc 1999:50:173-7.

29 Barham CP, Jones RL, Biddlestone LR, et al. Photothermal laser ablation of Barrett's oesophagus: endoscopic and histologic evidence of squamous reepithelialisation. Gut 1997;41:281-4.

30 Weston AP, Sharma P. Neodymium:yttrium-aluminum garnet contact laser ablation of Barrett's high grade dysplasia and early adenocarcinoma. Am J Gastroenterol 2002;97:2998-3006.

31 Eisen GM. Ablation therapy for Barrett's esophagus. Gastrointest Endosc 2003;58:760-9.

32 Kahaleh M, Van Laethem JL, Nagy N, et al. Long-term follow-up and factors predictive of recurrence in Barrett's esophagus treated by argon plasma coagulation and acid suppression. Endoscopy 2002;34:950-5.

33 Dulai GS, Jensen DM, Cortina G, et al. Randomized trial of argon plasma coagulation vs. multipolar electrocoagulation for ablation of Barrett's esophagus. Gastrointest Endosc 2005;61:232-40.

34 Hage M, Siersema PD, van Dekken H, et al. 5-Aminolevulinic acid photodynamic therapy versus argon plasma coagulation for ablation of Barrett's oesophagus: a randomized trial. Gut 2004;53:785-90.

35 Brandt $\mathrm{L}$, Blansky M, Kauvar DR. Repeat laser therapy of recurrent Barrett's epithelium: success with anacidity. Gastrointest Endosc 1995;41:267.

36 Sampliner RE, Camargo L, Fass R. Impact of esophageal acid exposure on the endoscopic reversal of Barrett's esophagus. Am J Gastroenterol 2002;97:270-2.

37 Barham CP, Jones RL, Biddlestone LR, et al. Photothermal laser ablation of Barrett's oesophagus: endoscopic and histological evidence of squamous reepithelialisation. Gut 1997:41:281-4.

38 Overholt B, Panjehpour M, Haydek J. Photodynamic therapy for Barrett's esophagus: follow-up in 100 patients. Gastrointest Endosc 1999;49:1-7.

39 Shand A, Dallal H, Palmer K, et al. Adenocarcinoma arising in columnar lined oesophagus following treatment with argon plasma coagulation. Gut 2001:48:580-1.

40 Van Laethem JL, Peny MO, Salmon I, et al. Intramucosal adenocarcinoma arising under squamous re-epithelialisation of Barrett's oesophagus. Gut $2000 \cdot 46: 574-7$

\section{Call for abstracts}

International Forum on Quality \& Safety in Health Care

18-20 April 2007, Palau De Congressos, Barcelona

Deadline: 25 September 2006

http://www.quality.bmipg.com 